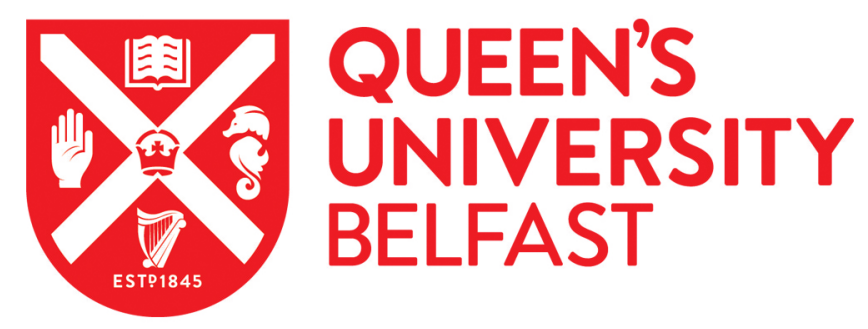

\title{
Impact of average household income and damage exposure on post- earthquake distress and functioning: A community study following the February 2011 Christchurch earthquake.
}

Dorahy, M. J., Rowlands, A., Renouf, C., Hanna, D., Britt, E., \& Carter, J. D. (2015). Impact of average household income and damage exposure on post-earthquake distress and functioning: A community study following the February 2011 Christchurch earthquake. British Journal of Psychology, 106(3), 526-543. https://doi.org/10.1111/bjop.12097

Published in:

British Journal of Psychology

Document Version:

Early version, also known as pre-print

Queen's University Belfast - Research Portal:

Link to publication record in Queen's University Belfast Research Portal

\begin{abstract}
Publisher rights
Copyright 2015 The Authors

This is the pre-peer reviewed version of the following article: Dorahy, M. J., Rowlands, A., Renouf, C., Hanna, D., Britt, E. and Carter, J. D. (2015), Impact of average household income and damage exposure on post-earthquake distress and functioning: A community study

following the February 2011 Christchurch earthquake. British Journal of Psychology, 106: 526-543., which has been published in final form at http://onlinelibrary.wiley.com/doi/10.1111/bjop.12097/abstract. This article may be used for non-commercial purposes in accordance with Wiley Terms and Conditions for Self-Archiving.

General rights

Copyright for the publications made accessible via the Queen's University Belfast Research Portal is retained by the author(s) and / or other copyright owners and it is a condition of accessing these publications that users recognise and abide by the legal requirements associated with these rights.
\end{abstract}

\section{Take down policy}

The Research Portal is Queen's institutional repository that provides access to Queen's research output. Every effort has been made to ensure that content in the Research Portal does not infringe any person's rights, or applicable UK laws. If you discover content in the Research Portal that you believe breaches copyright or violates any law, please contact openaccess@qub.ac.uk. 
Impact of average household income and damage exposure on post-earthquake distress and functioning: A community study following the February 2011

Christchurch earthquake

Martin J. Dorahy, Amy Rowlands, Charlotte Renouf

University of Canterbury, New Zealand

Donncha Hanna

The Queen’s University of Belfast, Northern Ireland

Eileen Britt, Janet D. Carter

University of Canterbury, New Zealand

Running head: INCOME \& DAMAGE EXPOSURE ON POST-EARTHQUAKE DISTRESS

Author Note

Martin J. Dorahy, Department of Psychology, University of Canterbury, Christchurch, New Zealand; The Cannan Institute, Belmont Private Hospital, Brisbane, Australia; Amy Rowlands, Charlotte Renouf, Eileen Britt, Janet D. Carter, Department of Psychology, University of Canterbury, Christchurch, New Zealand; Donncha Hanna, School of Psychology, the Queen's University of Belfast, Northern Ireland.

Correspondence concerning this article should be addressed to Martin J. Dorahy, Department of Psychology, University of Canterbury, Private Bag 4800, Christchurch, 8140, New Zealand. Email: martin.dorahy@canterbury.ac.nz 


\begin{abstract}
Posttraumatic stress, depression, and anxiety symptoms are common outcomes following earthquakes, and may persist for months and years. This study systematically examined the impact of neighborhood damage exposure and average household income on psychological distress and functioning in 600 residents of Christchurch, New Zealand, 4-6 months after the fatal February, 2011 earthquake. Participants were from highly affected and relatively unaffected suburbs in low, medium and high average household income areas. The assessment battery included the Acute Stress Disorder Scale, the depression module of the Patient Health Questionnaire (PHQ-9), and the Generalized Anxiety Disorder Scale (GAD-7), along with single item measures of substance use, earthquake damage and impact, and disruptions in daily life and relationship functioning. Controlling for age, gender and social isolation, participants from low income areas were more likely to meet diagnostic cut-offs for depression and anxiety, and have more severe anxiety symptoms. Higher probability of acute stress, depression and anxiety diagnoses was evident in affected versus unaffected areas, and those in affected areas had more severe acute stress, depression and anxiety symptoms. An interaction between income and earthquake effect was found for depression, with those from the low and medium income affected suburbs more depressed. Those from low income areas were more likely post-earthquake to start psychiatric medication and increase smoking. There was a uniform increase in alcohol use across participants. Those from the low income affected suburb had greater general and relationship disruption post-quake. Average household income and damage exposure make unique contributions to earthquakerelated distress and dysfunction.
\end{abstract}

Keywords: earthquake, distress, exposure, socioeconomic status 
The impact of average household income and exposure to neighborhood damage on post-earthquake psychological distress and functioning: A community study following the Christchurch 2011 earthquake

In the days, weeks, and months following a disaster, survivors can struggle to regain a sense of who they were before the event, as they try to adapt to various personal and resource losses, and to emotional reminders of their experiences (Bonanno, Brewin, Kaniasty, \& La Greca, 2010; Kar \& Bastia, 2006; McFarlane, 1988; Norris et al., 2002). As an unpredictable natural disaster, earthquakes especially test the capability of individuals and communities to cope with unexpected mass upheaval, disruptions and loss (Bödvarsdóttir \& Elklit, 2004).

The prevalence of psychological distress like depression, anxiety and posttraumatic stress after earthquakes ranges between $6 \%$ and $67 \%$, depending on whether assessment examined symptoms or disorders, and when the measures were taken (Armenian et al., 2002; Carr et al., 1995; Kiliç et al., 2006; Sharan, Chaudhary, Kavathekar \& Saxena, 1996; Zhou et al., 2013). For example, rates of posttraumatic stress disorder and major depressive episodes were 39\% and 18\%, respectively, when assessed 20 months after the Marmara earthquake in Turkey (Salcioğlu, Başoğlu, \& Livanou, 2003). Symptoms often reduce over time, but for a considerable number of individuals they linger for months and years (Carr et al., 1995; Goenjian, Steinberg, Najarian, Fairbanks, Tashjian, \& Pynoos, 2000; Kuwabara et al., 2008; Zhou et al., 2013). Carr et al. (1995) suggest that ongoing psychological symptoms following earthquakes are associated with the possibility of repeated aftershocks (Dorahy \& Kannis-Dymand, 2012) and continued disruptions associated with loss of property, displacement, domestic relocation, and infrastructure redevelopment. 
Earthquake-related symptoms may be particularly elevated among those with greater exposure to disruptions and displacement (Carr et al. 1997; Norris et al., 2002), such that those more physically affected by the earthquake (e.g., loss of house, displacement) have greater psychological symptoms (Dorahy \& Kannis-Dymand, 2012; Lima et al., 1989). Carr et al. (1995) reported that people with high levels of exposure to the 1989 Newcastle (Australia) earthquake had more general and posttraumatic symptom distress than those with lower exposure levels. Disruption (e.g., loss of home, displacement, change of employment) had a greater impact on general psychological distress (e.g., mood and anxiety symptoms) than posttraumatic distress. Yet, experiences of threat (e.g., personal injury, experiences of danger) had a similar elevated impact on both general and posttraumatic distress. General and posttraumatic distress were predicted by gender (female) and exposure, while general distress was further predicted by reduced social support, and posttraumatic distress by age (being older). Interestingly, perceived social support had no impact on posttraumatic stress symptoms at 6 months.

Other work has supported the link between distress and earthquake exposure in the form of personal losses and community destruction (Sattler, Glower de Alvarado, Blandon de Castro, Van Male, \& Vega, 2006; Sharan et al., 1996). A study 7 months after the magnitude 8.0 Sichuan (south-western China) earthquake (2008) found that loss of friends or neighbors, residential house damage or collapse, and proximity to the epicentre, were significant predictors of severe mental health problems among survivors (Chan et al., 2011). Losses may lead to a decline in social networks and support in affected communities which precedes any decline in psychological well-being, including the onset or worsening of depression (Kaniasty \& Norris, 1993). 
In short, factors associated with increased risk of earthquake-related distress include being female, experiencing displacement or relocation as a result of the earthquake, having heightened exposure to the aftermath, experiencing loss and destruction of a range of resources, having reduced social support, fearing ongoing earthquakes, and being older (Armenian et al., 2002; Bland et al., 1997; Carr et al., 1995; Dorahy \& Kannis-Dymand, 2012; Kiliç et al., 2006; Lima et al., 1989; Najarian, Goenjian, Pelkovitz, Mandel, \& Najarian, 2001; Sattler et al., 2006; Shindo, Kitamura, Tachibana, Honma, Someya, 2012; Zhou et al., 2013). Moreover, having less access to material and emotional resources heightens risk (Lima et al., 1989).

Several of the above factors associated with earthquake distress may be accounted for by Hobfoll's conservation of resources theory. This argues that individuals are motivated to accrue, cultivate and protect resources they attribute value to (e.g., Hobfoll, 2001, 2011). Resources fall into several categories, including object (e.g., house, car), condition (e.g., time with loved ones), personal characteristics (e.g., sense of optimism) and energy (e.g., adequate food). The loss of valued resources represents a central and salient feature in the production of stress and distress, which is more pertinent to psychological functioning than resource gain (Hobfoll, 2001). As such, people heavily affected by earthquake-related damage, destruction and loss should experience more distress than those less affected by these factors. Moreover, those heavily affected who have less financial assets are likely to experience greater distress as they lose the fewer resources they have.

The current study systematically examined the impact of average household income and degree of exposure to neighborhood damage on psychological outcome 46 months after the 20116.3 magnitude earthquake in Christchurch (New Zealand) which killed 185 people. This fatal earthquake occurred in the context of a prior 7.1 
magnitude earthquake (September $4^{\text {th }}$, 2010) and multiple, ongoing aftershocks that preceded and proceeded that event. Participants were residents of highly affected suburbs in low, medium and high average household income areas of Christchurch who were matched with residents of relatively unaffected suburbs from the same average income group. Affected suburbs experienced a range of problems including major property damage or loss, severe soil liquefaction (rising silt and water residue), and significant loss and disruption in utilities such as water, sewage and electricity. The primary outcome variables of anxiety, depression and posttraumatic stress symptoms were measured, as these are the most common symptoms following disasters (e.g., Kar \& Bastia, 2006; Kiliç et al., 2006; Lima et al., 1989; Madianos \& Evi, 2010; Norris, Perilla, Reid, Kanisty \& Lavizzo, 1999). Substance use and both general and relationship functioning were also examined.

Drawing on Hobfoll (2001) and following previous work (e.g., Dorahy \& Kannis-Dymand, 2012), participants in suburbs most physically affected by the earthquakes where expected to demonstrate greater symptom distress than those in relatively unaffected suburbs. In addition, those in the lowest income area, who were severely affected by the earthquakes, were predicted to have the most distress. Postearthquake substance use was expected to be higher in the low income areas that were physically affected. Moreover, in these participants general and relationship functioning were expected to be reduced. Gender, age, and lack of social support were used as covariates to further isolate the influence of physical damage/earthquake effect and income level, due to their association with post-earthquake variables (e.g., Sattler et al., 2006).

\section{Method}

\section{Participants}


Six hundred participants were recruited for this study and included 100 residents from each of six different suburbs of Christchurch. Suburbs sampled were chosen based on 1) degree of physical destruction caused by the earthquake (earthquake affected or relatively unaffected) and 2) average household income. Three of the six suburbs were severely physically affected by the earthquake, sustaining large-scale property loss and loss of utilities (water, sewage, electricity) for weeks and sometimes months. Many homes in these areas were 'red stickered' (building not safe to enter or occupy) and some-to-much of the land was 'red zoned' (land likely unsuitable for continued residential occupation). These three suburbs reflected low, medium and high average household income areas. Determination of the demographic characteristics and average household income of each suburb was based on 2006 census data (www.stats.govt.nz/Census/2006CensusHomePage.aspx).

Each of these three affected suburbs was matched to a suburb which was relatively unaffected by the earthquake, had the same demographic variables (e.g., number of people in suburb, average age and gender) and same average household income. The matched suburbs experienced comparatively lower level of damage to homes and properties, and had minimal loss of utilities. Thus, based on damage and income level, the six suburbs could be defined as: Affected Low income (AL), Relatively unaffected Low income (RL), Affected Medium income (AM), Relatively unaffected Medium income (RM), Affected High income (AH), and Relatively unaffected High income (RH). The low income suburbs had populations of around 3,200 people, with a median individual yearly income of approximately $\$ 22,000$. The medium income suburbs had populations of around 3,600 people, with a median individual yearly income of approximately $\$ 26,000$. The high income suburbs had 
populations of around 3,800 people and a median individual yearly income of approximately $\$ 33,500$.

The total sample ( $\mathrm{N}=600)$ ranged in age from 18-90 years $(M=49.69$ years; $S D=15.79)$. Mean age appeared to increase with income level, $F(2,595)=10.41$, $\mathrm{p}<.001$; the high income areas had the highest mean age $(M=50.49$ years; $S D=$ 13.89), followed by the medium $(M=48.48$ years; $S D=17.65)$ then the low income $(M=45.73$ years; $S D=14.86)$ suburbs. The communities did not differ in terms of gender with the overall sample consisting of 218 males (36.3\%) and 382 (63.7\%) females.

In total 2650 households were approached resulting in a valid response rate of 22.6\%. The households that did not respond were categorized as declining to participate (10.9\%) or vacant/no answer (66.5\%). Table 1 shows the response rate by suburb. There was a significant association between declining involvement and average suburb income, $\chi^{2}(2, n=2650)=41.70, p<.001 ; \varphi=.12$, with an increased frequency of households in the low (9.7\%) or medium (9.2\%) income areas declining compared to the high income suburbs. The phi coefficient indicates the effect size was very small. There was a significant association between declining participation and neighborhood damage, $\chi^{2}(1, n=2650)=33.13, p<.001 ; V=.11$, with $7.1 \%$ more households in the relatively unaffected area declining to take part. Again the effect size (Cramer’s V) was very small.

INSERT TABLE 1 ABOUT HERE

\section{Materials}


The structure and content of the survey was initially developed as part of an earlier study examining the September 2010 magnitude 7.1 earthquake in Christchurch (Dorahy \& Kannis-Dymand, 2012). It contained the Acute Stress Disorder Scale (ASDS; Bryant, Moulds, \& Guthrie, 2000), the Patient Health Questionnaire’s 9-item depression module (PHQ-9; Spitzer, Kroenke, \& Williams, 1999), and the Generalized Anxiety Disorder-7 scale (GAD-7; Spitzer, Kroenke, Williams, \& Löwe, 2006). For this study all items were anchored to currently occurring symptoms starting since the February $22^{\text {nd }} 2011$ earthquake and ongoing aftershocks. The ASDS was administered first, followed by the PHQ-9, and then the GAD-7.

Following administration of the standardized measures, age and gender were recorded and participants were asked single item questions regarding degree of social isolation, and changes in medication, alcohol, cigarette consumption, and recreational drug use since the February earthquakes. The response format, anchored to increases in substances, started with 'not applicable' and then ranged on a 5 point scale from 'not at all' to 'a significant amount'. Participants were also asked dichotomous response ('yes/no') questions regarding whether they lived without electricity, water, and sewage for two or more days following the earthquake, whether they had to move house as a result of the earthquake and whether they sought health and social service support post-earthquake. They also responded on a dichotomous scale to whether they had lost anything (e.g., house, family member, job) from the earthquake.

\section{Functioning}

Questions addressing daily and relationship functioning were also administered. These were assessed on a 0 (N/A) to 5 (extreme) point scale with participants asked about the degree to which the earthquakes had disrupted their work, 
household tasks, leisure activities, family unit, and relationships with partner, children, and family/friends. An exploratory factor analysis with principal axis factoring extraction was conducted on the seven functioning items. Both the scree plot and the Kaiser criterion suggested there were two distinct factors with no cross loading items. The first factor consisted of four items relating to disruption to relationships with children, the family unit, partner and extended family/friends (factor loadings ranged from .47-.81), and was named relationship functional disruptions. The second factor contained three items relating to disruption in social and leisure activities, household tasks and work outside the home (factor loadings ranged from .46-.70), and was named general functional disruptions.

\section{Distress markers}

The ASDS is a 19-item inventory based on DSM-IV (American Psychiatric Association, 1994) criteria for acute stress disorder, which is widely used in research and clinical settings (Bryant, Moulds \& Guthrie, 2000). Items assess dissociation (5), re-experiencing (4), avoidance (4), and arousal (6) symptoms on a Likert-type scale ranging from 1 (not at all) to 5 (very much). A diagnosis of acute stress disorder can be estimated if scores on the dissociation subscale are greater than 8 and the cumulative scores of the remaining 3 subscales are greater than 27 (Bryant et al., 2000; Bryant \& Harvey, 2000). The ASDS has demonstrated excellent psychometric properties, with Cronbach's alphas higher than .8 for total and subscale items (Bryant et al., 2000). A more recent study with Chinese earthquake survivors found that the four-factor structure for the ASDS was consistent with DSM-IV symptom clusters (Wang, Li, Shi, Zhang \& Shen, 2010). The ASDS, which requires a time frame of no longer than a month since the trauma, was included in the study because large earthquakes were continuing (e.g., two struck on June $13^{\text {th }} 2011$, measuring 6.3 and 
5.9). Thus, for many, trauma stimuli were still acute and ongoing. The ASDS also provides a good indication of posttraumatic stress disorder symptoms as it measures the three symptom types of DSM-IV PTSD.

The PHQ-9 reflects the nine items on the larger PHQ designed to assess depression. Participants rate how much they were bothered by each item on a 4-point Likert scale from 0 (not at all) to 3 (nearly every day). It has been used widely in primary care, specialist medical settings and the general population to offer both a severity rating for depression and a probable diagnosis (Spitzer et al., 1999). The continuous scale assessing severity of depression symptoms ranges from $0-27$, with scores above 5, 10, 15 and 20 representing mild, moderate, moderate-severe and severe levels of depression, respectively (Kroenke \& Spitzer, 2002; Kroenke, Spitzer, \& Williams, 2001; Kroenke, Spitzer, Williams \& Löwe, 2010). A probable diagnosis of major depressive disorder can be made if participants endorse 5 or more of the 9 symptoms as experienced 'more than half the days,' but the $9^{\text {th }}$ item, assessing for suicidal ideation, is included if endorsed 'several days.' In addition, one of the first two items, assessing mood and loss of interest, must be endorsed for a probable diagnosis of major depressive disorder (Kroenke et al., 2010). The PHQ-9 is a reliable and valid measure of depression severity (Kroenke et al., 2001, 2010) and is highly correlated with Major Depressive Episode and Major Depressive Disorder as diagnosed with the Structured Clinical Interview for DSM-IV (SCID; Cannon, Tiffany, Coon, Scholand, McMahon, \& Leppert, 2007).

The GAD-7 scale is a seven item measure of general anxiety (Spitzer, Kroenke, Williams, \& Lowe, 2006) based around the DSM-IV diagnostic criteria for generalized anxiety disorder (GAD). Whilst it was primarily designed to assess GAD, it has been found to be a good screen for other anxiety disorders (Kroenke et al., 
2010). Items assess how frequently participants are bothered by specific anxiety symptoms. Responses are made on a 4-point Likert scale ranging from 0 (not at all) to 3 (nearly every day). Summed scores range between 0 and 21, with scores over 5, 10, and 15 reflecting mild, moderate and severe anxiety, respectively (Kroenke et al., 2010; Löwe et al., 2008; Spitzer et al., 2006). Scores over 8 are thought to be indicative of an anxiety disorder (Kroenke, Spitzer, Williams, Monahan, \& Löwe, 2007), with Ebell (2008) suggesting that a cut-off of nine provides better detection of those with an anxiety disorder (sensitivity) while not compromising the ability to rule out those without an anxiety disorder (specificity). Thus, we used a cut-off of nine to detect an anxiety disorder. The GAD-7 has good reliability and validity as a selfreport measure of anxiety in the general population (Löwe et al., 2008; Spitzer et al., 2006). It was used here as an efficient and valid assessment of anxiety severity (Spitzer et al., 2006).

\section{Procedure}

A door-to-door survey methodology was utilized, with participants 'cold called' and assessed at their own home. Following informed written consent, participants were read each question by the interviewer. The survey took approximately 20-30 minutes to complete. Upon completion, participants were debriefed, asked if they would like to participate in a follow-up study in approximately 5 months, and were given an information sheet offering free support and counseling services in Christchurch along with several self-help educational resources. Data collection commenced 4 months after the February $22^{\text {nd }}$ earthquake and had a two-month window. Notably, shortly after the start of data collection 2 large aftershocks were experienced on the same day (June $13^{\text {th }}, 2011,1.00 \mathrm{pm}$, 
Magnitude 5.9; 2.20pm, Magnitude 6.4; http://www.canterburyquakelive.co.nz/). The study was approved by the University of Canterbury Human Ethics Committee.

\section{Analyses}

Associations between average income level (low, medium, high) and earthquake effect (relatively unaffected, affected) for the categorical variables of 1) diagnoses (acute stress, depression, anxiety) and 2) the use of prescription medicines were assessed with Pearson Chi-square tests (using Yates' continuity correction for 2x2 contingency tables) with Cramer's V and phi coefficients (as appropriate) as estimates of effect size. To test the differences and interactions between average income and earthquake effect on interval/ratio measures 2-factor multivariate analysis of covariances (MANCOVAs) were conducted. Separate MANCOVAs were conducted for the dependent variables of; 1) distress (acute stress, depression, anxiety) scores, 2) ASDS subscales, 3) substance use and 4) functioning scores. In each case age and gender were included as covariates. For the distress scores of acute stress, depression and anxiety, social isolation was introduced as an additional covariate (this variable was not related to ASDS subscales, substance use/drug use and functional disruption scores). MANCOVA was chosen to control for the familywise error rate and take account of the theoretical and statistical relationships between the scales. Effect sizes were estimated with partial eta squared. All analyses were computed using the Statistical Package for the Social Sciences (SPSS Version 19).

\section{Results}

\section{Earthquake effects across suburbs}

Supporting the experimental differentiation between affected and relatively unaffected suburbs, 51\% of those living in affected suburbs moved from their homes as a direct result of the earthquake, compared to $13 \%$ in the relatively unaffected suburbs, $\chi^{2}(1, n=600)=96.58, p<.001 ; \phi=.40$. Those in high income (45\%) suburbs 
reported moving house more than those in low (28\%) and medium (24\%) income suburbs, $\chi^{2}(2, n=598)=22.75, p<.001 ; V=.20$. In terms of losing utilities (water, sewage, electricity), 94.7\% of those in the affected suburbs responded affirmatively, compared to $45.2 \%$ in the relatively unaffected areas, $\chi^{2}(1, n=599)=174.67, p<.001$; $\phi=.54$. Again, despite the overall high level of utility loss across the sample, the high income area (88\%) was significantly more affected than the low (54\%) and medium $(68 \%)$ areas, $\chi^{2}(2, n=599)=58.90, p<.001 ; V=.31$. Seeking health and mental health service following the earthquake was more prevalent in the affected suburbs $(\mathrm{AL}=$ $39 \%$; $\mathrm{AM}=35 \%, \mathrm{AH}=18 \%$, total $=31 \%)$ versus the relatively unaffected areas $(\mathrm{RL}$ $=28 \%, \mathrm{RM}=12 \%, \mathrm{RH}=12 \%$, total $=18 \%), \chi^{2}(1, n=598)=13.08, p<.001 ; \phi=.15$, and was more prevalent in low income (34\%) compared to medium (25\%) and high (15\%) income areas, $\chi^{2}(2, n=598)=18.64, p<.001 ; \mathrm{V}=.18$. Seeking social services support was also higher amongst affected suburbs (96\% vs $77 \%), \chi^{2}(1, n=594)=47.88$, $p<.001 ; \phi=.28$, while the high income areas (99\%) were more likely to seek this support compared to the low (82\%) and medium (79\%) income areas, $\chi^{2}(2$, $n=598)=36.66, p<.001 ; V=.25$.

\section{Diagnoses across suburb average income}

Table 2 shows the diagnostic cut-offs for acute stress disorder, depression and anxiety across suburb average income levels. The sample demonstrated prevalence rates of $41.2 \%$ for acute stress, $38.3 \%$ for depression, and $42.8 \%$ for anxiety. There was no significant association between acute stress diagnosis and income level. However, there was a significant association between depression diagnosis and income level, $\chi^{2}(2, n=600)=13.72, p=.001 ; V=.15$, with higher levels of depression diagnosis in the lowest income (47.5\%) compared to the medium (38\%) or high (29.5\%) income areas. When this trend was further explored in relation to depression 
severity, significant associations between income level and both mild, $\chi^{2}$ (2, $n=600)=8.34, p=.025 ; V=.12$, and moderate depression, $\chi^{2}(2, n=600)=9.53, p=.009$; $V=.13$ were evident. The highest reported incidence for mild depression was in the low income (30\%), compared to the medium (19\%) and high (20\%) income areas. Similarly for moderate depression, the highest rates were reported in the low income (15.5\%), compared to the medium (13\%) and high (6\%) income suburbs. There was no association between income level and either moderate-severe or severe depression; perhaps partly due to the low number indicating high depression levels ( $2 \%$ and $1.8 \%$ respectively).

A significant association was found between anxiety diagnosis and income level, $\chi^{2}(2, n=600)=36.03, p<.001 ; V=.25$, with higher levels of anxiety diagnosis in the lowest income (59.5\%), compared to the medium (38\%) and high (31\%) income areas. Further exploration found a significant association between mild anxiety diagnosis and income level, $\chi^{2}(2, n=600)=29.35, p<.001 ; V=.22$, with higher levels in the lowest income (43\%), compared to the medium (22.5\%) and high (22\%) income areas. A similar trend was observed for moderate anxiety, $\chi^{2}(2, n=600)=8.02, p=.018$; $V=.12$, with higher levels in the low (15\%), compared to medium (9.5\%) and high (6.5\%) income suburbs. There was also a significant association between severe anxiety diagnosis and income, $\chi^{2}(2, n=600)=9.72, p=.008$; $V=.13$ but in this case the medium income had the highest score (7\%), followed by the high (2.5\%) and low (1.5\%) income areas. Only 3.7\% of the total sample reported severe anxiety.

INSERT TABLE 2 ABOUT HERE

\section{Diagnoses across Earthquake effect}


There was a significant association between acute disorder diagnosis and earthquake effect, $\chi^{2}(1, n=600)=20.07, p<.001 ; \phi=.19$, with those respondents from the affected suburbs having a higher frequency of acute stress disorder (50.3\%) than the relatively unaffected suburbs (32\%; see Table 2). Similarly, there was a significant association between depression diagnosis and earthquake effect, $\chi^{2}$ (1, $n=600)=46.26, p<.001 ; \phi=.28$; affected suburbs had more respondents meeting cut-off for a depression diagnosis (52\%) than the relatively unaffected suburbs (24.7\%). When this trend was further explored in relation to distress severity, similar significant associations were found for mild, $\chi^{2}(1, n=600)=7.91, p<.005 ; \phi=.12$ and moderate, $\chi^{2}(1, n=600)=28.29, p<.001 ; \phi=.22$, depression, with higher levels of mild (28\%) and moderate (18.7\%) depression in affected compared to relatively unaffected suburbs ( $18 \%$ \& $4.3 \%$ respectively). There was no significant association between earthquake effect and either moderate-severe or severe depression.

Finally, there was a significant association between anxiety diagnosis and earthquake effect, $\chi^{2}(1, n=600)=12.01, p<.001 ; \phi=.14$, with those from the affected suburbs having a higher frequency of anxiety diagnosis (50\%) compared to the relatively unaffected suburbs (35.7\%). There was no significant association between mild anxiety diagnosis and earthquake effect. However, earthquake effect was significantly associated with moderate anxiety, $\chi^{2}(1, n=600)=7.2, p<.007 ; \phi=.11$, with higher rates in affected suburbs (13.7\%) compared to relatively unaffected areas (7\%). Similarly there was a significant association between severe anxiety and earthquake effect, $\chi^{2}(1, n=600)=3.92, p=.049 ; \phi=.09$ with higher rates in affected suburbs $(5.3 \%$ vs $2 \%)$.

The association of suburb income and earthquake effect with distress scores 
Table 3 shows the descriptive and reliability statistics for stress, depression and anxiety measures for the total sample.

\section{INSERT TABLE 3 ABOUT HERE}

A 2-factor MANCOVA with the three distress scales (acute stress, depression \& anxiety) as dependent measures revealed the significant covariates of gender, Pillai’s trace $=.12 ; F(3,587)=25.74 ; p<.001 ; \eta_{\rho}^{2}=.12$, age, Pillai’s trace $=.05 ; F(3$, 587)=9.46; $p<.001 ; \eta_{\rho}^{2}=.05$, and social isolation, Pillai's trace $=.03 ; F(3,587)=25.74$; $p<.001 ; \eta_{\rho}^{2}=.03$. Furthermore there were significant multivariate main effects of income, Pillai's trace=.06; $F(6,1176)=5.80 ; p<.001 ; \eta_{\rho}^{2}=.03$, and earthquake effect, Pillai's trace $=.11 ; F(3,587)=24.00 ; p<.001 ; \eta_{\rho}{ }^{2}=.11$. There was also a significant multivariate interaction, Pillai’s trace $=.05 ; F(6,1176)=5.16 ; p<.001 ; \eta_{\rho}^{2}=.11$. Average income produced a significant main effect on anxiety scores, $F(2,589)=7.03 ; p=.001$; $\eta_{\rho}^{2}=.02$, with respondents from the lowest income areas reporting higher anxiety than the medium ( $p=.005)$ and high $(p=.003)$ income suburbs (see table 4). Average income produced no main effect for acute stress or depression scores. The main effect for earthquake effect showed those living in affected suburbs had higher acute stress, $F(1,589)=31.07 ; p<.001 ; \eta_{\rho}^{2}=.05$, depression, $F(1,589)=72.10 ; p<.001 ; \eta_{\rho}{ }^{2}=.11$, and anxiety, $F(1,589)=41.57 ; p<.001 ; \eta_{\rho}^{2}=.07$ scores.

The only significant interaction between average income and earthquake effect was on the depression scale, $F(2,589)=8.82 ; p<.001 ; \eta_{\rho}^{2}=.03$. Respondents from low and medium income areas living in affected suburbs had significantly higher depression scores $(p<.05)$ than those from low and medium income areas living in 
relatively unaffected suburbs. However, there was no significant influence of earthquake effect on depression scores in the high income suburbs.

\section{INSERT TABLE 4 ABOUT HERE}

\section{Average income and Earthquake effect on ASDS subscales}

A 2-factor MANCOVA with the 4 ASDS subscales (dissociation, intrusion, avoidance \& arousal) as dependent measures revealed the significant covariates of gender, Pillai's trace $=.11 ; F(4,587)=18.29 ; p<.001 ; \eta_{\rho}{ }^{2}=.11$ and age, Pillai's trace $=.04 ; F(4,587)=6.36 ; p<.001 ; \eta_{\rho}^{2}=.04$. Furthermore there were significant multivariate main effects of income, Pillai's trace $=.03 ; F(8,1176)=2.03 ; p=.04$; $\eta_{\rho}{ }^{2}=.01$, and earthquake effect, Pillai's trace $=.71 ; F(4,587)=11.16 ; p<.001 ; \eta_{\rho}{ }^{2}=.07$. There was no significant multivariate interaction. The only subscale that demonstrated a main effect on average income was dissociation, $F(2,590)=3.26 ; p=.039 ; \eta_{\rho}^{2}=.01$, with respondents from medium income areas $(\mathrm{m}=10.46$; $\mathrm{SD}=4.33)$ having significantly higher mean dissociation scores $(p=.042)$ than respondents from high income areas $(m=9.53 ; S D=4.16)$. There were significant main effects for earthquake effect on dissociation, $F(1,590)=33.13 ; p<.001 ; \eta_{\rho}^{2}=.05$; intrusions, $F(1$, 590)=11.90; $p=.001 ; \eta_{\rho}^{2}=.02$; avoidance, $F(1,590)=4.38 ; p=.037 ; \eta_{\rho}^{2}=.01$ and arousal, $F(1,590)=31.14 ; p<.001 ; \eta_{\rho}^{2}=.05$. Living in an affected area was related to significantly higher mean scores on all four ASDS subscales (see table 5). 


\section{The association of suburb average income and earthquake effect with substance} use

No significant association was found between starting psychiatric medication and earthquake effect, with 7\% of those in relatively unaffected suburbs reporting starting medication compared to $9.1 \%$ in affected suburbs. However, there was a significant association between starting medication and average income level, $\chi^{2}$ (2, $n=596)=10.10, p=.006 ; V=.13$, with higher medication commencement in lowest income (12.1\%) compared to medium (8.6\%) and high (3.5\%) income areas.

A 2-factor MANCOVA with increase in alcohol, cigarette and recreational drug use as dependent measures revealed the significant covariates of gender, Pillai's trace $=.02 ; F(3,586)=4.30 ; p=.005 ; \eta_{\rho}^{2}=.02$, and age, Pillai's trace $=.07 ; F(3$, 586)=14.12; $p<.001 ; \eta_{\rho}^{2}=.07$. Furthermore there was a significant multivariate main effect of average income, Pillai's trace $=.04 ; F(6,1174)=3.84 ; p=.001 ; \eta_{\rho}^{2}=.02$, but no significant main effect of earthquake effect or interaction. Income produced a significant main effect on increased cigarette, $F(2,588)=9.50 ; p<.001 ; \eta_{\rho}{ }^{2}=.03$, and recreational drug use, $F(2,588)=4.19 ; p=.031 ; \eta_{\rho}^{2}=.01$. Respondents from low $(p=.021)$ and medium $(p<.001)$ income areas reported more increases in smoking than high income areas. Respondents from medium $(p=.014)$ income areas also reported more increases in recreational drug use than the high income group. There was no significant main effect of income on alcohol use. Thus, although alcohol use demonstrated significantly greater increases than smoking $(p<.001)$ or drug use $(p<.001)$, these increases appeared relatively uniform across income areas (see table 6). 


\section{Average income and earthquake effects on functioning}

A 2-factor MANCOVA with the 2 functional disruption scales (relationship and general disruptions) as dependent measures revealed the significant covariates of gender, Pillai's trace $=.02 ; F(2,584)=7.09 ; p=.001 ; \eta_{\rho}^{2}=.02$, and age, Pillai's trace $=.05 ; F(2,584)=16.85 ; p<.001 ; \eta_{\rho}^{2}=.05$. There were significant multivariate main effects of average income, Pillai's trace $=.09 ; F(4,1170)=13.02 ; p<.001 ; \eta_{\rho}{ }^{2}=.04$, and earthquake effect, Pillai's trace $=.02 ; F(3,584)=73.08 ; p<.001 ; \eta_{\rho}^{2}=.02$, and a significant multivariate interaction, Pillai’s trace $=.05 ; F(4,1170)=7.03 ; p<.001$;

$\eta_{\rho}{ }^{2}=.02$. Income produced a significant main effect on general functional disruption scores, $F(2,585)=25.70 ; p<.001 ; \eta_{\rho}^{2}=.08$, with respondents from low $(p<.001)$ and high $(p<.001)$ income areas reporting more disruption than medium income areas (see table 7). There was no significant main effect of income on relationship disruption scores.

The main effect for earthquake effect showed that participants living in the affected suburbs had significantly higher relationship disruption, $F(1,585)=18.21$; $p<.001 ; \eta_{\rho}^{2}=.03$ and general disruption, $F(1,585)=146.28 ; p<.001 ; \eta_{\rho}^{2}=.20$, than those living in relatively unaffected suburbs (see table 7). There was a significant interaction between average income and earthquake effect on relationship disruption, $F(2,585)=3.11 ; p=.045 ; \eta_{\rho}^{2}=.01$. Respondents from low income areas living in affected suburbs had significantly higher relationship disruption $(p<.05)$ than respondents from low and medium income areas living in relatively unaffected suburbs. Respondents from the high income areas living in affected suburbs had significantly higher relationship disruption $(p<.05)$ than respondents from low income, relatively unaffected suburbs. There was a significant interaction between average 
income and earthquake effect on general disruption, $F(2,585)=14.27 ; p<.001 ; \eta_{\rho}^{2}=.05$. The highest general disruption mean scores were reported by the low income affected group and was significantly higher $(p<.05)$ than all the other 5 groups. The second highest mean score was the high income affected group which reported significantly higher mean scores $(p<.05)$ than the medium income affected group and all of the relatively unaffected groups (irrespective of income level). Finally the medium income affected group reported significantly higher mean scores $(p<.05)$ than the medium and low income relatively unaffected groups.

INSERT TABLE 7 ABOUT HERE

\section{Discussion}

The current study is one of the first to systematically assess the impact of average household income and level of physical damage on psychological distress in a community sample following a fatal earthquake. Those in the physically damaged (affected) suburbs were more likely to have moved house, lost utilities and accessed health/mental health and social services after the earthquake compared to those in relatively unaffected suburbs. Despite the considerable physical impact across the whole sample, within the affected suburbs, those in the high income area were more likely to have moved house after the earthquake (perhaps in part because they had the means to) and lost utilities. High income affected participants were more likely to access social services, while low income affected participants were more likely to access health and mental health services. Mental health problems were common in the total sample, with over a third reaching diagnostic cut-offs for acute stress disorder, anxiety and/or depression. Moreover, alcohol use increased across the whole sample, 
potentially as a means of chemically self-regulating heightened stress. However, even though the high income suburbs reported higher levels of utility loss and moving from their homes as a result of the earthquake, mental health problems were more evident in low income areas. The low income areas reported higher anxiety symptoms, even when age, gender and social isolation were controlled for, and were more likely to reach diagnostic cut-offs for mild and moderate depression and anxiety. Perhaps on account of their higher psychological symptoms, those in low income areas were more likely to have started psychiatric medication post-earthquake, and at least compared to the high income group, reported an increase in cigarette use. The low income areas reported more daily functioning problems (e.g., work, household tasks, leisure activities) compared to the medium income areas.

Individuals in affected areas experienced more acute stress, depression and anxiety symptoms than those in relatively unaffected areas, and were more likely to reach diagnostic cut-offs for acute stress disorder, mild and moderate depression and moderate and severe anxiety. These same participants also experienced more problems in relationship and daily life functioning.

While neighborhood context and financial resources were associated with earthquake-related outcome, the combination of earthquake effect and average income level seemed less important to understanding outcome than each factor uniquely, as their interaction was only meaningful for depression and functional disruptions. Most evidently, those with less financial resources who were from the most affected neighborhoods, reported more mood-related problems and greater disruptions in relationship and daily life functioning. In short, these findings suggest that lower average income and level of physical damage have discrete and unique impacts on earthquake-related distress. Low average income leaves people 
particularly prone to anxiety and depression, with increased exposure to physical damage post-earthquake heightening mood difficulties further. Increased physical exposure independently heightened anxiety and depression, but appeared to have a unique impact on increasing posttraumatic stress symptoms. Heightened distress in participants residing in areas most physically affected by the earthquake is consistent with other studies (Carr et al., 1995).

Across the whole sample, the earthquakes continued to have a very significant impact on mental health functioning 4-6 months after the fatal earthquake. Level of acute stress disorder diagnosis across suburbs ranged from 30\%-54\%. For depression and anxiety diagnosis, the range was 23\%-72\% and 27\%-67\%, respectively. These rates are consistent with prior research conducted around 6 months post-earthquake (e.g., Kuwabara et al., 2008). Thus, the psychological impact of earthquakes is not limited to those highly affected by personal and neighborhood damage, or low average household incomes. Rather earthquakes appear to have a more far-reaching and chronic impact. However, even with the powerful predictors of age, gender and social isolation accounted for, average household income and degree of neighborhood damage continued to be salient indicators of poorer psychological outcome.

With reference to posttraumatic stress symptoms in the current study, residing in areas severely affected by the earthquake, had a uniform impact on increasing all four posttraumatic stress symptom markers (i.e., dissociation, intrusions, avoidance, arousal). Diagnostic criteria for both acute stress and posttraumatic stress disorders are based on exposure to traumatic events in which acute harm or possible death to self or others occurs. Other studies have shown that posttraumatic stress symptoms following earthquakes are associated with direct trauma exposure (Zhou et al., 2013). Yet the current study reported increased posttraumatic stress symptoms in those 
whose neighborhoods and houses experienced the greatest physical damage. It is unlikely that such people were disproportionately exposed to death, harm and destruction when the earthquake hit, as fatalities, building collapse, injuries and people being trapped, were for the most part isolated to the city centre, which draws people from across all suburbs. Thus there is something about living day-to-day with the physical ongoing aftermath of an earthquake that seems to be associated with posttraumatic stress symptoms, beyond any contribution from direct exposure. This may be due to 1) the insidious nature of ongoing stress in affected areas (Dorahy \& Kannis-Dymand, 2012; Scott \& Stradling, 1994), 2) the notion that living with distressing reminders in the context of ongoing disruption may maintain already elevated dissociative symptoms and inhibit effective conceptual processing of the whole series of events (Holmes, Brewin \& Hennessy, 2004; Lyttle, Dorahy, Hanna \& Huntjens, 2010), or 3) subjective cognitions and emotions (e.g., fear, shame, helplessness) maintained by the environmental cues. This study is one of many that suggest posttraumatic stress symptoms are not limited to events involving direct harm or threatened death (e.g., Alcorn, O'Donovan, Patrick, Creedy, \& Devilly, 2010; Dorahy \& Kannis-Dymand, 2012; Scott \& Stradling, 1994).

Whilst being exposed post-earthquake to more neighborhood physical destruction appears to heighten psychological distress, in this study, unlike some others (e.g., Dorahy \& Kannis-Dymand, 2012; Carr et al., 1995; Lima et al., 1989) distress was not simply related to increased exposure. Rather, average income influenced the severity of distress in those living in physically affected areas, especially for depression. The current research supports average income as an important psychosocial contributor, beyond the impact of known risk factors for poor mental health outcome following an earthquake, such as age, gender, social isolation 
and exposure, found both here and in other studies (Armenian et al., 2002; Carr et al., 1997; Kiliç et al., 2006; Lima et al., 1989; Najarian et al., 2001; Sattler et al., 2006; Zhou et al., 2013). Residing in a lower income area was associated with greater anxiety and depression after the earthquakes, and more functional disruption in daily life. Potentially as a result of these increased difficulties, individuals in low income areas were more likely to commence medication use since the earthquake, and to selfsoothe via increased cigarette consumption.

Following an earthquake, living in a low income area may contribute to greater psychological and functional difficulties due to mediating variables including lack of occupational, social and financial resources. Conservation of resources theory suggests that low income may be a chronic stressor, increasing psychological distress as a result of limited resource access and resource accumulation (Ennis, Hobfoll, \& Schröder, 2000; Hobfoll, 2001, 2011). Acute resource loss (e.g., from an earthquake), in the context of chronic lower resources, punctuates the limited resources available to people in low income areas, heightening distress further (Ennis et al., 2000). Thus, personal and communal resource limitations are a central factor creating heightened distress in low income areas following earthquakes. The current findings suggest that income level should be considered a gross social indicator of outcome following earthquakes. Resources should be especially targeted towards low income areas in order to reduce the psychological impact and facilitate adjustment.

The only variables that responded to the interaction between income and earthquake effect were depression and relationship disruption. Both were elevated in those from low income areas who had more damage exposure. Previous work has shown a link between depression and relationship difficulties (e.g., Fincham, Beach, Harold \& Osborne, 1997). What is unclear in the current study is the causal 
relationship, and whether post-earthquake depressions lead to relationship problems, or whether the earthquake heightened relationship discord and daily functioning difficulties which contributed to lower mood. Both directional associations may be evident and dependent on variables such as gender (Fincham et al., 1997).

While average income level produced increases in anxiety and depression regardless of level of effect, it had no impact on acute stress symptoms. Only neighborhood damage exposure was related to posttraumatic stress symptoms. Thus, posttraumatic stress symptoms appeared sensitive to neighborhood physical exposure, but insensitive to income level. The finding that different psychosocial factors produce different outcomes has been reported previously (Carr et al., 1995). Ongoing exposure to earthquake aftermath appears to punctuate psychological functioning in a manner that produces the intrusive and avoidant symptoms characteristic of acute and posttraumatic stress. Socioeconomic variables, like average income seem to have a more eroding, rather than punctuating, impact on post-earthquake psychopathology.

The findings of this study were strengthened by a design that allowed methodological control of average household income and neighborhood exposure variables in a large community sample assessed face-to-face at a relatively short period after the earthquake. Known psychosocial variables effecting psychological outcomes were statistically controlled. Nonetheless, the study had limitations. Arguably the most pressing was the fact that two-thirds of households were either unoccupied when approached, or vacant. In all areas, but especially in the affected areas, many homes were uninhabitable after the earthquake. Previous occupants may have been more severely psychologically affected than those still residing in the neighborhood. Thus, an accurate representation of the psychological impact of those most affected may not have been achieved. The external validity of the study was also 
impacted by low and medium income areas having a slightly higher 'decline to participate' rates (approx. 11\%) than the high income area (3.5\%), and slightly more 'declines' in the relatively unaffected area. Related to this, the methodology invited one adult participant in each household to be interviewed, and in some cases those who answered the door deferred to another member of the household to be interviewed. Anecdotally, this was sometimes a person most affected by the earthquake and, at other times, least affected. More stringent control of this feature, such as randomly inviting a specific person in each household (e.g., a male, a female, the oldest, the youngest, etc), may have produced more representative findings.

The current results suggest that in cities exposed to fatal earthquakes, distress is a widespread phenomenon not limited to average income or degree of physical damage experienced to area of residence. Yet, once other known distress-related variables are controlled, both income level and degree of ongoing neighborhood damage appear to make an independent, and in some cases joint, contribution to psychological distress and functional disruption. Thus, resource planning and distribution should initially extend across the whole region affected by the event (i.e., affected and relatively unaffected areas), with greater and ongoing resources further being targeted to areas more affected and those with less income. Given that income level significantly contributed to increased depression and anxiety symptoms, it should not be assumed that more affected areas have the highest psychosocial need. Lower income has its own significant impact on post-earthquake distress regardless of level of exposure to the aftermath of an earthquake. 


\section{References}

Alcorn, K. L., O'Donovan, A., Patrick, J. C., Creedy, D., \& Devilly, G. J. (2010). A prospective longitudinal study of the prevalence of post-traumatic stress disorder resulting from childbirth events. Psychological Medicine, 40, 18491859. Doi: $10.1017 / S 0033291709992224$.

American Psychiatric Association. (1994). Diagnostic and statistical manual of mental disorders (4 ${ }^{\text {th }}$ Edition). Washington, DC: Author.

Armenian, H. K., Morikawa, M., Melkonian, A. K., Hovanesian, A., Akiskal, K., \& Akiskal, H. (2002). Risk Factors for Depression in the Surviors of the 1988 Earthquake in Armenia. Journal of Urban Health: Bulletin of the New York Academy of Medicine, 79 (3), 373-382. Doi: 10.1093/jurban/79.3.373

Bland, S., O’Leary, E. S., Farinaro, E., Jossa, F., Krogh, V., Violanti, J., \& Trevisan, M. (1997). Social networks disturbances and psychological distress following earthquake evacuation. Journal of Nervous Mental Disorders, 186, 188-194

Bödvarsdóttir, I., \& Elklit, A. (2004). Psychological reactions in Icelandic earthquake survivors. Scandinavian Journal of Psychology, 45 (1), 3-13.

Doi: 10.1111/j.1467-9450.2004.00373.x

Bonanno, G. A., Brewin, C. R., Kaniasty, K., \& La Greca, A. M. (2010). Weighing the cost of disasters: Consequences, risks, and resilience in individuals, families, and communities. Psychological Science in the Public Interest, 11, 149.Doi: $10.1177 / 1529100610387086$

Bryant, R. A., Moulds, M. L., \& Guthrie, R. M. (2000). Acute Stress Disorder Scale: A self- report measure of acute stress distress. Psychological Assessment, 12, 61-68. 
Bryant, R. A., \& Harvey, A. G. (2000). Acute stress disorder: A handbook of theory, assessment, and treatment. Washington, DC: American Psychological Association.

Cannon, D. S., Triffany, S. T., Coon, H., Scholand, M. B., McMahon, W. M., \& Leppert, M. F. (2007) The PHQ-9 as a brief assessment of lifetime major depression. Psychological Assessment, 19, 247-251.

Canterbury Quake Live. (2012). Christchurch New Zealand. Retrieved from http://www.canterburyquakelive.co.nz

Carr, V. J., Lewin, T. J., Webster, R. A., Hazell, P. L., Kenardy, J. A., \& Carter, G. L. (1995). Psychological sequelae of the 1989 Newcastle earthquake: I.

Community disaster experiences and psychological morbidity 6 months postdisaster. Psychological Medicine, 25, 539-555. Doi:

$10.1017 / \mathrm{S} 0033291700033468$

Carr, V., Lewin, T., Webster, R., Kenardy, J., Hazell, P., Carter, G. (1997).

Psychological sequelae of the 1989 Newcastle earthquake: II. Exposure and morbidity profiles during the first 2 years post-disaster. Psychological Medicine, 27, 167-178. Retrieved from http://journals.cambridge.org/article_S0033291796004278

Chan, C., Wang, C., Qu, Z., Lu, B., Ran, M., Ho, A., Yuan, Y., Zhang, B., Wang, X., Zhang, X. (2011). Posttraumatic Stress Disorder Symptoms Among Adult Survivors of the 2008 Sichuan Earthquake in China. Journal of Traumatic Stress, 24, 295-302. Doi: 10.1002/jts.20645.

Dorahy, M. J., \& Kannis-Dymand, L. (2012). Psychological distress following the 2010 Christchurch earthquake: A community assessment of two differentially 
affected suburbs. Journal of Loss and Trauma, 17, 203-217. Doi:

$10.1080 / 15325024.2011 .616737$

Ebell, M. H. (2008). Diagnosis of Anxiety Disorders in Primary Care. American Family Physician, 78, 501-502.

Ennis, N. E., Hobfoll, S. E., \& Schröder, K. E. E. (2000). Money doesn’t talk, it swears: How economic stress and resistance resources impact inner-city women’s depressive mood. American Journal of Community Psychology, 28, 149-173. Doi: 10.1023/A:1005183100610

Fincham. F. D., Beach, S. R. H., Harold, G. T., \& Osborne, L. N. (1997). Marital satisfaction and depression: Different causal relationships for men and women. Psychological Science, 8, 351-357.

Goenjian, A.K., Steinberg, A.M., Najarian, L.M., Fairbanks, L.A., Tashjian, M., \& Pynoos, R.S. (2000). Prospective study of posttraumatic stress, anxiety, and depressive reactions after earthquake and political violence. American Journal of Psychiatry, 157, 895-911.

Hobfoll, S. E. (2001). The influence of culture, community, and the nested-self in the stress process: Advancing Conversation of Resource theory. Applied Psychology: An Interational Review, 50, 337-369. Doi: 10.1111/14640597.00062

Hobfoll, S. E. (2011). Conservation of resources theory: Its implications for stress, health and resilience. In S. Folkman (Ed.), The Oxford handbook of stress, health and coping (pp. 127-147). Oxford: Oxford University Press.

Holmes, E. A., Brewin, C. R., \& Hennessy, R. G. (2004). Trauma films, information processing, and intrusive memory development. Journal of Experimental Psychology: General, 133, 3-22. Doi: 10.1037/0096-3445.133.1.3 
Kaniasty, K., \& Norris, F. H. (1993). Test of social support deterioration model in the context of natural disaster. Journal of Personality and Social Psychology, 64, 395-408.

Kar, N., \& Bastia, B. K. (2006). Post-traumatic stress disorder, depression and generalized anxiety disorder in adolescents after a natural disaster: A study of comorbidity. Clinical Practice and Epidemiology in Mental Health, 2, 17.

Kiliç, C., Aydin, I., Taskintuna, N., Ozcurumez, G., Kurt, G., Eren, E., ... Zileli, L. (2006). Predictors of psychological distress in survivors of the 1999 earthquakes in Turkey: Effects of relocation after the disaster. Acta Psychiatrica Scandinavica, 114, 194-202.

Kroenke, K., \& Spitzer, R. L. (2002). The PHQ-9: A new depression diagnostic and severity measure. Psychiatric Annals, 32, 1-7.

Kroenke, K., Spitzer, R. L. \& Williams, J. B. W. (2001). The PHQ-9 Validity of a brief depression severity measure. Journal of General Internal Medicine, 16, 606-613.

Kroenke, K., Spitzer, R. L., Williams, J. B., \& Löwe, B. (2010). The Patient Health Questionnaire somatic, anxiety, and depressive symptom scales: A systematic review. General Hospital Psychiatry, 32, 345-359. Doi:

10.1016/j.genhosppsych.2010.03.006

Kroenke, K., Spitzer, R. L., Williams, J. B., Monahan, P. O., \& Löwe, B. (2007). Anxiety disorders in primary care: Prevalence, impairment, comorbidity, and detection. Annals of Internal Medicine, 146, 317-325.

Kuwabara, H., Shioiri, T., Toyabe, S., Kawamura, T., Koizumi, M., Ito-Sawamura., Someya, T. (2008). Factors impacting on psychological distress and 
recovery after the 2004 Niigata-Chuetsu earthquake,Japen: Communitybased study. Psychiatry and Clinical Neurosciences; 62, 503-507.

Doi: 10.1111/j.1440-1819.2008.01842.x

Lima, B. R., Chavez, H., Samaniego, N., Pompei, M. S., Pai, S., Santacruz, H., \& Lozano, J. (1989). Disaster severity and emotional disturbance: Implications for primary mental health care in developing countries. Acta Psychiatrica Scandivanica, 79, 74-82.

Löwe, B., Decker, O., Muller, S., Brahler, E., Schellberg, D., Herzog, W., \& Herzberg, P. Y., (2008). Validation and standardization of the Generalized Anxiety Disorder Screener (GAD-7) in the general population. Medical Care, 46, 266-274. Doi: 10.1097/MLR.0b013e318160d093

Lyttle, N., Dorahy, M., Hanna, D., \& Huntjens, R. J. C. (2010). Conceptual and perceptual priming and dissociation in chronic posttraumatic stress disorder. Journal of Abnormal Psychology, 119, 777-790. Doi: 10.1037/a0020894

Madianos, M., \& Evi, K. (2010). Trauma and natural disaster: The case of earthquakes in Greece. Journal of Loss and Trauma, 15, 138-150. Doi: $10.1080 / 15325020903373185$

McFarlane, A. C. (1988). The phenomenology of posttraumatic stress disorders following a natural disaster. Journal of Nervous and Mental Disease, 176, 2229. Doi: $10.1097 / 00005053-198801000-00003$

Najarian, L., Goenjian, A., Pelcovitz, D., Mandel, F., \& Najarian, B. (2001). The effect of relocation after a natural disaster. Journal of Trauma Stress, 4, 511-526.

Norris, F. H., Friedman, M. J., Watson, P. J., Byrne, C. M., Diaz, E., \& Kaniasty, K. 
(2002). 60,000 disaster victims speak. Part I. An empirical review of the empirical literature, 1981-2001. Psychiatry, 65, 207-239. Doi:

10.1521/psyc.65.3.207.20173

Norris, F., Perilla, J., Reid, J., Kanisty, K., and Lavizzo, E. (1999). Stability and change in stress, resources, and psychological distress following natural disaster: Findings from Hurricane Andrew. Anxiety, Stress, and Coping, 12, 363-396. Doi: 10.1080/10615809908249317

Salcioğlu, E., Bașoğlu, M., \& Livanou, M. (2003). Long-term Psychological Outcomes for Non-Treatment-Seeking Earthquake Survivors in Turkey. Journal of Mental Disorders, 191, 154-160. Doi: 10.1097/00005053200303000-00003

Sattler, D., Glower de Alvarado, A., Blandon de Castro, N., Van Male, R., Zetino, A., \& Vega, R. (2006). El Salvador earthquakes: Relationships among acute disorder symptoms, depression, traumatic event exposure, and resource loss. Journal of Traumatic Stress, 19, 879-893.

Scott, M. J., \& Stradling, S. G. (1994). Post-traumatic stress disorder without the trauma. British Journal of Clinical Psychology, 33, 71-74. Doi: 10.1111/j.2044-8260.1994.tb01095.x

Sharan, P., Chaudhary, G., Kavathekar, S., \& Saxena, S. (1996). Preliminary report of psychiatric disorders in survivors of a severe earthquake. American Journal of Psychiatry; 153, 556-558.

Shindo, M., Kitamura, H., Tachibana, A., Honma, H., \& Someya, T. (2012). Early psychological distress among sufferers after the 2011 Northern Nagano prefecture earthquake. Psychiatry and Clinical Neurosciences, 2012, 66, 454456. Doi: 10.1111/j.1440-1819.2012.02366.x 
Spitzer, R., Kroenke, K., \& Williams, J. B W. (1999). Validation and utility of a selfreport version of PRIME-MD: The primary care study. Journal of the American Medical Association, 282, 1737-1744. Doi:

10.1001/jama.282.18.1737

Spitzer, R., Kroenke, K., Williams, J. B. W., \& Löwe, B. (2006). A brief measure for assessing generaliszed anxiety disorder. Archives of Internal Medicine, 166, 1092-1097. Doi: 10.1001/archinte.166.10.1092.

Statistics New Zealand. New Zealand Government. (2012). Retrieved from http://www.stats.govt.nz/Census/2006CensusHomePage.aspx

Wang, L., Li, Z., Shi, Z., Zhang, Y., \& Shen, J. (2010). Factor structure of acute stress disorder symptoms in Chinese earthquake victims: A confirmatory factor analysis of the Acute Stress Disorder Scale. Personality and Individual Differences, 48, 798-802. Doi: 10.1016/j.paid.2010.01.027

Zhou X, Kang L, Sun X, Song H, Mao W, Hunag X, Zhang Y, Li J (2013) Prevalence and risk factors of PTSD among adult survivors six months after the Wenchuan earthquake. Comprehensive Psychiatry, http://dx.doi.org/10.1016/j.comppsych.2012.12.010 
Table 1

Response rate by suburb

\begin{tabular}{llll}
\hline $\begin{array}{l}\text { Earthquake affected } \\
\text { by average income }\end{array}$ & $\begin{array}{l}\text { Number of } \\
\text { households } \\
\text { approached (N) }\end{array}$ & $\begin{array}{l}\text { Declined } \\
\text { involvement \% (n) }\end{array}$ & $\begin{array}{l}\text { Vacant or no } \\
\text { answer \% (n) }\end{array}$ \\
\hline $\begin{array}{l}\text { Affected low income } \\
\text { Relatively unaffected } \\
\text { low income }\end{array}$ & 757 & $10.7(65)$ & $72.8(441)$ \\
$\begin{array}{l}\text { Affected medium } \\
\text { income }\end{array}$ & 289 & $14.9(113)$ & $61.8(544)$ \\
$\begin{array}{l}\text { Relatively unaffected } \\
\text { medium income }\end{array}$ & 434 & $4.8(14)$ & $60.6(175)$ \\
$\begin{array}{l}\text { Affected high income } \\
\text { Relatively unaffected } \\
\text { high income }\end{array}$ & 352 & $17.7(77)$ & $69.2(257)$ \\
\hline
\end{tabular}


Table 2

Frequency/percentage of acute stress, depression and anxiety diagnoses across suburbs ( $\mathrm{n}=100$ per suburb)

\begin{tabular}{|c|c|c|c|c|c|c|}
\hline Average income & \multicolumn{2}{|c|}{ Low } & \multicolumn{2}{|c|}{ Medium } & \multicolumn{2}{|c|}{ High } \\
\hline $\begin{array}{l}\text { Distress } \\
\text { Diagnosis }\end{array}$ & $\begin{array}{l}\text { Relatively } \\
\text { Unaffecte } \\
\text { d }\end{array}$ & $\begin{array}{c}\text { Affecte } \\
\text { d }\end{array}$ & $\begin{array}{l}\text { Relatively } \\
\text { Unaffecte } \\
\text { d }\end{array}$ & $\begin{array}{c}\text { Affecte } \\
\text { d }\end{array}$ & $\begin{array}{c}\text { Relatively } \\
\text { Unaffecte } \\
\text { d }\end{array}$ & $\begin{array}{l}\text { Affecte } \\
\text { d }\end{array}$ \\
\hline Acute Stress & 32 & 54 & 34 & 54 & 30 & 43 \\
\hline Depression & 23 & 72 & 27 & 49 & 24 & 35 \\
\hline $\begin{array}{ll}\text { o } & \text { Mild } \\
& \text { Depression }\end{array}$ & 21 & 39 & 16 & 22 & 17 & 23 \\
\hline $\begin{array}{ll}\text { o } & \text { Moderate } \\
& \text { Depression }\end{array}$ & 1 & 30 & 7 & 19 & 5 & 7 \\
\hline $\begin{array}{ll}\text { o } & \text { Moderate- } \\
\text { Severe } \\
\text { Depression }\end{array}$ & 1 & 2 & 3 & 2 & 0 & 4 \\
\hline $\begin{array}{ll}\text { o } & \text { Severe } \\
& \text { Depression }\end{array}$ & 0 & 1 & 1 & 6 & 2 & 1 \\
\hline Anxiety & 52 & 67 & 28 & 48 & 27 & 35 \\
\hline o Mild Anxiety & 42 & 44 & 15 & 28 & 23 & 21 \\
\hline $\begin{array}{l}\text { Moderate } \\
\text { Anxiety }\end{array}$ & 9 & 21 & 8 & 11 & 4 & 9 \\
\hline $\begin{array}{ll}\text { o } & \text { Severe } \\
\text { o } & \text { Anxiety }\end{array}$ & 1 & 2 & 5 & 9 & 0 & 5 \\
\hline
\end{tabular}


Table 3

Overall descriptive and reliability statistics for each scale

\begin{tabular}{lccccc}
\hline Distress measure & Mean & $\begin{array}{c}\text { Standard } \\
\text { Deviation }\end{array}$ & Range & $\begin{array}{c}\text { Possible } \\
\text { Range }\end{array}$ & $\begin{array}{c}\text { Cronbach’s } \\
\text { Alpha }\end{array}$ \\
\hline Acute Stress & 40.23 & 13.45 & $19-82$ & $19-95$ & .91 \\
o Dissociation & 9.98 & 4.16 & $5-23$ & $5-25$ & .76 \\
o Intrusion & 8.88 & 3.35 & $4-20$ & $4-20$ & .71 \\
o Avoidance & 7.24 & 3.17 & $4-20$ & $4-20$ & .69 \\
o Arousal & 14.13 & 5.42 & $6-30$ & $6-30$ & .84 \\
Depression & 5.33 & 4.93 & $0-25$ & $0-27$ & .87 \\
Anxiety & 5.59 & 4.62 & $0-21$ & $0-21$ & .91 \\
\hline
\end{tabular}


Table 4

Means (standard deviations) for distress measures across suburb average income level and earthquake effect

\begin{tabular}{|c|c|c|c|c|}
\hline $\begin{array}{c}\text { Average } \\
\text { income level }\end{array}$ & Earthquake effect & $\begin{array}{c}\text { Acute Stress } \\
\text { Mean (sd) }\end{array}$ & $\begin{array}{c}\text { Depression } \\
\text { Mean (sd) }\end{array}$ & $\begin{array}{c}\text { Anxiety } \\
\text { Mean } \\
\text { (sd) }\end{array}$ \\
\hline \multirow[t]{3}{*}{ Low } & $\begin{array}{l}\text { Relatively } \\
\text { unaffected }\end{array}$ & $\begin{array}{c}37.08 \\
(10.88)\end{array}$ & $3.77(2.63)$ & $\begin{array}{c}5.93 \\
(3.36)\end{array}$ \\
\hline & Affected & $\begin{array}{c}43.96 \\
(11.43)\end{array}$ & $8.51(4.03)$ & $8(4)$ \\
\hline & Total & $\begin{array}{c}40.52 \\
(11.65)\end{array}$ & $6.14(4.14)$ & $\begin{array}{c}6.96 \\
(3.83)\end{array}$ \\
\hline \multirow[t]{3}{*}{ Medium } & $\begin{array}{l}\text { Relatively } \\
\text { unaffected }\end{array}$ & $\begin{array}{c}38.54 \\
(13.30)\end{array}$ & $3.94(4.81)$ & $\begin{array}{c}4.01 \\
(4.96)\end{array}$ \\
\hline & Affected & $\begin{array}{c}43.69 \\
(14.52)\end{array}$ & $6.72(6.31)$ & $\begin{array}{c}6.66 \\
(5.40)\end{array}$ \\
\hline & Total & $\begin{array}{c}41.11 \\
(14.13)\end{array}$ & $5.33(5.76)$ & $\begin{array}{c}5.33 \\
(5.34)\end{array}$ \\
\hline \multirow[t]{3}{*}{ High } & $\begin{array}{l}\text { Relatively } \\
\text { unaffected }\end{array}$ & $\begin{array}{c}36.96 \\
(13.76)\end{array}$ & $3.91(4.38)$ & $\begin{array}{c}3.75 \\
(3.51)\end{array}$ \\
\hline & Affected & $\begin{array}{c}41.17 \\
(14.77)\end{array}$ & $5.14(4.84)$ & $\begin{array}{c}5.18 \\
(4.74)\end{array}$ \\
\hline & Total & $\begin{array}{c}39.07 \\
(14.39)\end{array}$ & $4.53(4.65)$ & $\begin{array}{c}4.47 \\
(4.22)\end{array}$ \\
\hline \multirow[t]{2}{*}{ Total } & $\begin{array}{l}\text { Relatively } \\
\text { unaffected }\end{array}$ & $\begin{array}{c}37.53 \\
(12.69)\end{array}$ & $3.87(4.04)$ & $\begin{array}{c}4.56 \\
(4.11)\end{array}$ \\
\hline & Affected & $\begin{array}{c}42.94 \\
(13.67)\end{array}$ & $6.79(5.31)$ & $\begin{array}{c}6.61 \\
(4.87)\end{array}$ \\
\hline
\end{tabular}


Table 5:

Descriptive statistics for ASDS symptom subscales

\begin{tabular}{lcccc}
\hline Suburb & Dissociation & Intrusion & Avoidance & Arousal \\
& Mean (sd) & Mean (sd) & Mean (sd) & Mean (sd) \\
& & & & \\
\hline Relatively unaffected & $9.09(3.88)$ & $8.44(3.13)$ & $6.98(3.19)$ & $13.02(5.04)$ \\
Affected & $10.88(4.24)$ & $9.32(3.51)$ & $7.50(3.13)$ & $15.24(5.56)$ \\
Total & $9.98(4.16)$ & $8.88(3.35)$ & $7.24(3.17)$ & $14.13(5.41)$ \\
\hline
\end{tabular}


Table 6

Descriptive statistics for alcohol, cigarette and drug use across suburb income levels

\begin{tabular}{clc}
\hline Increase in & Average income level & $\begin{array}{c}\text { Mean (Standard } \\
\text { Deviation) }\end{array}$ \\
\hline Alcohol use & Low & $1.62(.96)$ \\
& Medium & $1.52(1)$ \\
& High & $1.59(1.1)$ \\
\multirow{5}{*}{ Cigarette use } & Total & $1.58(1.02)$ \\
& Low & $.55(1.21)$ \\
& Medium & $.66(1.36)$ \\
Recreational drug use & High & $.17(.72)$ \\
& Total & $.46(1.14)$ \\
& Low & $.12(.4)$ \\
& Medium & $.17(.33)$ \\
& High & $.05(.38)$ \\
& Total & $.11(.38)$ \\
\hline
\end{tabular}


Table 7

Descriptive statistics for relationship and general functional disruptions across suburb average income.

\begin{tabular}{llcc}
\hline $\begin{array}{c}\text { Average income } \\
\text { level }\end{array}$ & Earthquake effect & $\begin{array}{c}\text { Relationship } \\
\text { functioning } \\
\text { disruptions }\end{array}$ & $\begin{array}{c}\text { General } \\
\text { functioning } \\
\text { disruptions }\end{array}$ \\
\hline Low & $\begin{array}{l}\text { Relatively } \\
\text { unaffected }\end{array}$ & $4.37(2.52)$ & $6.39(1.83)$ \\
& Affected & $6.48(3.58)$ & $10.35(2.57)$ \\
Total & $5.62(3.22)$ & $8.39(2.98)$ \\
Medium & Relatively & $4.76(2.81)$ & $5.21(2.88)$ \\
& unaffected & $5.63(3.37)$ & $7.51(3.21)$ \\
& Affected & $5.20(3.12)$ & $6.37(3.26)$ \\
Tigh & Total & $5.41(2.31)$ & $6.97(2.35)$ \\
& Relatively & & \\
Totalfected & Affected & $5.84(3.03)$ & $8.43(3.05)$ \\
& Total & $5.62(2.70)$ & $7.70(2.91)$ \\
& Relatively & $4.97(2.56)$ & $6.20(2.50)$ \\
& unaffected & & \\
& Affected & $5.98(3.34)$ & $8.76(3.18)$ \\
\hline
\end{tabular}

